\title{
Does functional MRI detect activation in white matter? A review of emerging evidence, issues, and future directions
}

\author{
Jodie R. Gawryluk ${ }^{1+}$, Erin L. Mazerolle ${ }^{2 \dagger}$ and Ryan C. N. D'Arcy ${ }^{3,4 *}$ \\ ${ }^{1}$ Division of Medical Sciences, Department of Psychology, University of Victoria, Victoria, BC, Canada \\ ${ }^{2}$ Department of Radiology, Faculty of Medicine, University of Calgary, Calgary, AB, Canada \\ ${ }^{3}$ Applied Sciences, Simon Fraser University, Burnaby, BC, Canada \\ ${ }^{4}$ Fraser Health Authority, Surrey Memorial Hospital, Surrey, BC, Canada
}

\section{Edited by:}

Thomas J. Grabowski, University of Washington School of Medicine,

USA

Reviewed by:

Matthew D. Budde, Medical College

of Wisconsin, USA

Kevin C. Chan, University of

Pittsburgh, USA

${ }^{*}$ Correspondence:

Ryan C. N. D'Arcy, Health Science and Innovation, Surrey Memorial

Hospital, Fraser Health Authority Central City Tower, Suite 400 -

13450 - 102nd Avenue, Surrey,

BC V3T OH1, Canada

e-mail: rdarcy@sfu.ca

these authors have contributed equally to this work.
Functional magnetic resonance imaging ( $f M R I)$ is a non-invasive technique that allows for visualization of activated brain regions. Until recently, fMRI studies have focused on gray matter. There are two main reasons white matter $\mathrm{fMRI}$ remains controversial: (1) the blood oxygen level dependent (BOLD) fMRI signal depends on cerebral blood flow and volume, which are lower in white matter than gray matter and (2) fMRI signal has been associated with post-synaptic potentials (mainly localized in gray matter) as opposed to action potentials (the primary type of neural activity in white matter). Despite these observations, there is no direct evidence against measuring $f M R I$ activation in white matter and reports of $\mathrm{fMRI}$ activation in white matter continue to increase. The questions underlying white matter fMRI activation are important. White matter fMRI activation has the potential to greatly expand the breadth of brain connectivity research, as well as improve the assessment and diagnosis of white matter and connectivity disorders. The current review provides an overview of the motivation to investigate white matter $\mathrm{fMRI}$ activation, as well as the published evidence of this phenomenon. We speculate on possible neurophysiologic bases of white matter fMRI signals, and discuss potential explanations for why reports of white matter fMRI activation are relatively scarce. We end with a discussion of future basic and clinical research directions in the study of white matter fMRI.

Keywords: functional magnetic resonance imaging, white matter, brain connectivity, corpus callosum, internal capsule

\section{MOTIVATION TO INVESTIGATE WHITE MATTER fMRI}

Functional magnetic resonance imaging (fMRI) is used to visualize the neuroanatomical regions associated with brain function. The most commonly used technique for fMRI, blood oxygenation level dependent (BOLD) contrast, was first demonstrated in the early 1990s (Ogawa et al., 1992). Since then, fMRI has broadened our understanding of how the brain functions under both healthy and diseased conditions (e.g., Rosen et al., 1998; Dolan, 2008; Haller and Bartsch, 2009; Rosen and Savoy, 2012). Although fMRI continues to grow in popularity in both research and clinical settings, the full potential of this technique remains untapped because fMRI activity has historically not been considered to be detectable in white matter tissue (Logothetis and Wandell, 2004). In spite of this, fMRI studies often produce activation in white matter and consequently there has been much debate over whether this activation is a true or false representation of underlying neural activity. There are two main reasons that white matter fMRI is controversial. First, BOLD signal relies on cerebral blood volume and flow, which are three to seven times lower in white matter (Rostrup et al., 2000; Preibisch and Haase, 2001; Helenius et al., 2003). However, the vasculature and perfusion of white matter (Figure 1) are capable of supporting hemodynamic changes that are detectable with BOLD fMRI [see Section White Matter Vasculature, Cerebral Blood Flow (CBF), and Cerebral Blood Volume (CBV)]. Second, the primary source of fMRI signal is thought to arise from post-synaptic potentials (which occur mainly in gray matter) as opposed to action potentials (e.g., Logothetis et al., 2001; but see e.g., Smith et al., 2002). However, neither of these statements exclude the possibility, and there is no direct evidence against the possibility of measuring fMRI activation in white matter.

White matter contains the connections between specialized processing regions and comprises approximately $50 \%$ of the human brain (Black, 2007; Arai and Lo, 2009; Harris and Attwell, 2012). The functional significance of white matter has been established by extensive lesion and anatomic studies, which have demonstrated the importance of intact white matter for normal brain function, and have implicated white matter damage and disconnections in numerous neurologic and psychiatric diseases (e.g., Catani and ffytche, 2005). A tool to non-invasively investigate the functional dynamics of white matter would substantially broaden current approaches to the study of brain connectivity, and may provide considerable insight into white matter diseases, such as multiple sclerosis. 

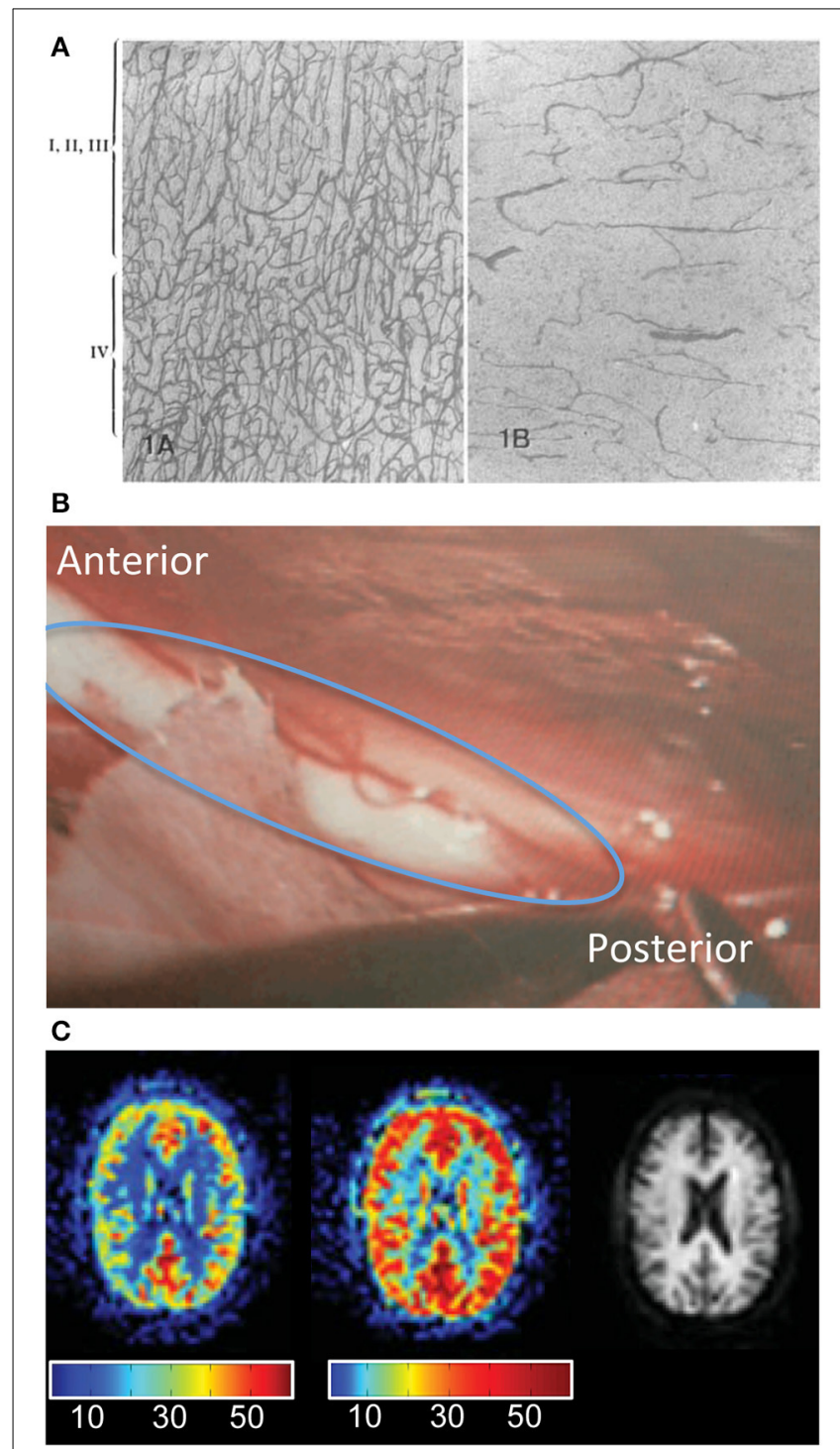

FIGURE 1 | The vasculature and perfusion of the white matter of the human brain. (A) Capillary density for various layers of the cortex (left panel) compared to white matter (right panel). Fixed human brains were embedded in paraffin, sectioned ( 10 microns) and stained by means of Goldner's trichrome-method (reproduced with permission; Lierse and Horstmann, 1965). (B) Blood vessels on the surface of the corpus callosum (circled in blue). Photo captured during neurosurgery for corpus callosotomy (photo credit: R. D'Arcy). (C) Detection of white matter perfusion with arterial spin labeling MRI. Cerebral blood flow maps with different scale bars in order to better view gray matter perfusion (left) and white matter perfusion (middle). The right image shows the anatomy for reference (reproduced with permission; Van Osch et al., 2009).

\section{PREVIOUS REPORTS OF WHITE MATTER FMRI ACTIVATION BOLD fMRI}

The majority of reports of BOLD fMRI activation in white matter involve the corpus callosum (Supplementary Table 1). Tettamanti et al. (2002) published a key report of white matter fMRI activation, in which a cluster was observed in the genu of the corpus callosum associated with a visuo-motor interhemispheric transfer task, the Poffenberger paradigm. In the Poffenberger task, light flashes are presented briefly (approximately $100 \mathrm{~ms}$ ) to the right or left visual hemifield, and participants must respond with either the contralateral (crossed) or ipsilateral (uncrossed) hand (Poffenberger, 1912). Tettamanti et al. (2002) findings were confirmed by Omura et al. (2004), Weber et al. (2005), and Gawryluk et al. (2009). The involvement of the anterior corpus callosum in the Poffenberger paradigm is the most well-established example of white matter fMRI activation.

Other interhemispheric transfer tasks have been used to target posterior regions of the corpus callosum. One such task is referred to as the Sperry paradigm, in recognition of the seminal work by Sperry and colleagues in which the function of the corpus callosum was probed by studying on split-brain patients (e.g., Gazzaniga et al., 1965; Myers and Sperry, 1985). In the Sperry task, word stimuli (for which the left hemisphere is relatively specialized) and face stimuli (for which the right hemisphere is relatively specialized) are presented briefly to the right or left visual hemifield. Crossed conditions involve presenting stimuli to the contralateral hemisphere (e.g., presenting word stimuli to the right hemisphere via the left visual field). D'Arcy et al. (2006) employed a Sperry task and an exploratory data analysis approach. Activation in the splenium of the corpus callosum activation could be observed, providing the first fMRI evidence of posterior callosal activation associated with an interhemispheric transfer task. Mazerolle et al. (2008) expanded and refined the approach taken by D'Arcy et al. (2006) by employing whole brain coverage, acquiring data at high field $(4 \mathrm{~T})$, and using a general linear model-based analysis technique. Splenium activation was observed in approximately $21 \%$ of individuals, as well as at the group level when liberal thresholds were applied $(p<0.005$ uncorrected; Figure 2). Gawryluk et al. (2011a) went on to functionally map the corpus callosum within subjects, showing distinct areas of callosal activation for the Poffenberger and Sperry interhemispheric transfer tasks (Figure 2).

Recently, Fabri et al. (2011) noted that "a rising number of researchers have been reporting fMRI activation in white matter, particularly the corpus callosum." Consequently, Fabri et al. (2011) sought to create a topographical map of the corpus callosum using data acquired from healthy participants at $1.5 \mathrm{~T}$ who completed tactile, gustatory, visual, and motor tasks. The results indicated that the corpus callosum was activated anteriorly by taste, at the midpoint by motor tasks, at the midpoint and posteriorly by tactile tasks, and posteriorly by visual stimuli. The central motor activation and posterior visual activation is consistent with previous findings from interhemispheric transfer tasks (Gawryluk et al., 2011a).

In addition to tasks aimed at eliciting interhemispheric transfer, tasks for investigating interhemispheric interactions have also been associated with callosal activation. Brandt et al. (2000) reported negative signal change in the occipital white matter containing the optic radiations contralateral to the visually stimulated hemisphere (uncorrected $p<0.001$ ). However, this is the only report of task-related negative signal changes in white matter, making it difficult to interpret. Aramaki et al. (2006) reported corpus callosum activation associated with interhemispheric interactions during bimanual coordination. 


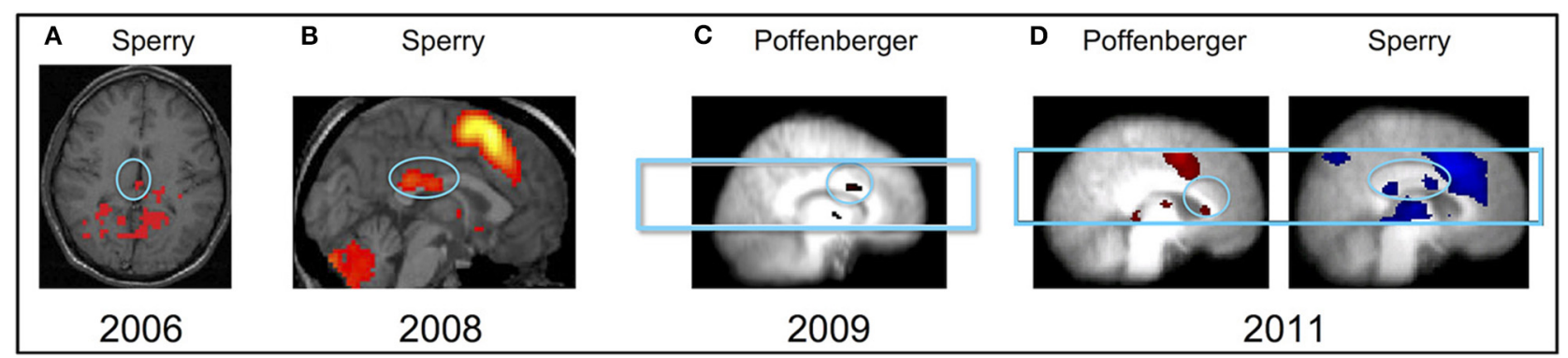

FIGURE 2 | Examples of white matter fMRI activation from studies published in 2006-2011. (A) An exploratory study of white matter activation by D'Arcy et al. in 2006 used a Sperry interhemispheric transfer task and detected activation near the splenium of the corpus callosum. This initial study led to (B) a prospective study of fMRI activation in white matter, which used a similar task and also revealed activation in the posterior corpus callosum. A follow up study, (C) aimed to improve sensitivity to the detection of white matter fMRI activation, used a Poffenberger interhemispheric transfer task and detected a cluster of activation in the anterior corpus callosum. Taken together, this series of studies led to (D), an investigation of whether different tasks could be used to functionally map different regions of the corpus callosum in the same group of individuals. The results were consistent with previous work and showed activation in the anterior corpus callosum during the Poffenberger task and posterior corpus callosum activation during the Sperry task.
Other conditions under which corpus callosum activation has been observed include a study of native signers viewing American Sign Language sentences with inflectional morphology (genu of the corpus callosum; Newman et al., 2010). Wang et al. (2013) used fMRI to study the neural correlates of acupuncture and detected activation in the posterior corpus callosum.

Outside of the corpus callosum, BOLD fMRI activation has been reported in the internal capsule. Mosier and colleagues reported activation associated with swallowing in the internal capsule, as well as the corpus callosum (Mosier et al., 1999a). Gawryluk et al. (2011b) found that activation could be detected in the internal capsule during a motor task (finger tapping), which was later confirmed by Mazerolle et al. (2013). In addition, white matter fMRI activation was observed for both healthy controls and Alzheimer's patients during a memory task (various white matter regions; Weis et al., 2011). Thyreau et al. (2012) also found a large number of white matter voxels above threshold in an investigation of random effects group statistics using a large database sample $(N>1500)$.

The studies reviewed above employed a task-based approach to investigate activation; that is, activation associated with the task/stimuli was evaluated. Activation associated with reaction time has also been explored in the context of white matter. In a multi-study analysis, Yarkoni et al. (2009) reported fMRI signal changes associated with reaction time in the right lateral genu of the corpus callosum, as well as in parts of the posterior corona radiata bilaterally (among gray matter regions). Shuster et al. (2014) used a similar reaction time based analysis of fMRI data related to speech production and detected activation in the mid-to-posterior corpus callosum.

Functional connectivity has also been observed in white matter during rest (i.e., task-free BOLD fMRI). Ding et al. (2013) examined temporal correlations of BOLD sensitive signals associated with resting state fMRI. Specifically, resting state fMRI data were used to evaluate the strength of functional connectivity within white matter tracts, which were defined using DTI tractography. Time courses from seed regions in the corpus callosum and optic radiations were considered. The results showed that functional connectivity was significantly greater for voxels within the same white matter tract than for random voxels (matched for distance from the seed). Thus, the correlation patterns associated with the seed regions were anisotropic: greater correlations were observed along white matter tracts than in other directions.

A small body of work exists that has attempted to better understand the factors related to sensitivity to BOLD fMRI activation in white matter. In an effort to increase sensitivity to the detection of fMRI signal in white matter, Gawryluk et al. (2009) investigated the underlying physics of white matter fMRI activation. The results showed that sensitivity to white matter clusters could be improved when T2-weighting was increased. However, this effect appears to be due to a general sensitivity increase from combining $\mathrm{T} 2 *$ - and T2-weighting, rather than a white matter specific effect (McWhinney et al., 2012). In another effort to increase sensitivity to the detection of white matter fMRI signal, Fraser et al. (2012) compared hemodynamic response functions (HRFs) in white and gray matter, and found similar response characteristics with reduced amplitude in white matter. Mazerolle et al. (2013) showed that field strength increases sensitivity to white matter fMRI activation, just as had been previously shown for gray matter. These studies have made progress toward understanding sensitivity to white matter activation; however, improving sensitivity to white matter activation remains an active area of research (discussed further in Sections Sensitivity and Artifacts and Basic Research).

In order to better understand the relationship between white matter activation and the activated network in gray matter, functionally-guided tractography has been applied. Mazerolle et al. (2010) used tractography to verify that regions of callosal activation were structurally connected to cortical regions activated by an interhemispheric transfer task (Figure 3). Thus, there is an anatomic basis for the notion that white matter fMRI activation corresponds with activated distributed brain networks. These findings also highlighted the potential value of combining white matter fMRI activation and diffusion tensor imaging (DTI) tractography methods for brain connectivity research, an 


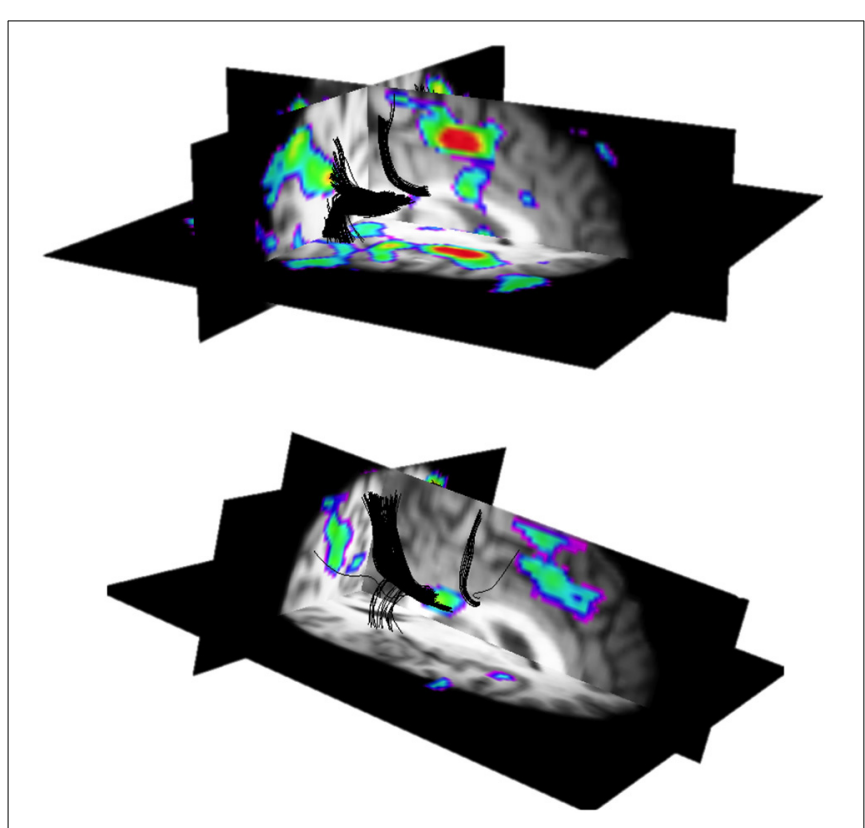

FIGURE 3 | 3D views of white matter fMRI activation co-localized to functionally-guided tractography in two subjects. An interhemispheric transfer task was used to elicit gray and white matter activation (rainbow color scale). Tracts (black) were seeded from regions of gray matter activation to determine whether the white matter activation was structurally connected to activation in gray matter. This work provided evidence for the anatomic basis of white matter activation; that is, regions of white matter activation are structurally connected to the activated network in gray matter. A discussion of individual variability in the location of callosal activation can be found in (Mazerolle et al., 2010). Figures were generated from data selected from (Mazerolle et al., 2010). contribution of white matter. In the immediate term, the evidence to-date raises questions regarding the underlying characteristics of the fMRI signal, and its relationship to white matter tissue.

\section{DIFFUSION fMRI}

In addition to the BOLD fMRI studies of white matter activation outlined in Section BOLD fMRI, there is emerging evidence that diffusion contrast might be sensitive to activity-dependent changes in white matter. Diffusion as a functional contrast mechanism has been reported for gray matter (e.g., Darquié et al., 2001; Williams et al., 2013). Task-correlated diffusivity changes are thought to represent structural changes induced by neuralactivity-related cell swelling (Le Bihan, 2012). Recently, diffusion fMRI has been used to detect activation in white matter, specifically in the mouse optic nerve (Spees et al., 2013; Lin et al., 2014). Changes in white matter fractional anisotropy (FA), a tissue microstructure metric derived from DTI, have also been reported for a visual task; however, FA must be averaged across large tracts of interest in order to observe this effect (Mandl et al., 2008). While more work is needed to (1) understand the physiological bases of functional contrast measured using diffusion, (2) improve the sensitivity of diffusion fMRI to activation, and (3) understand the impact of tissue type on functional diffusion contrast, diffusion fMRI remains an exciting alternative approach to understand the functional dynamics of the brain. Because diffusion fMRI contrast is not thought to rely on hemodynamic changes, it has potential to confer significant advantages for detecting white matter activation over BOLD fMRI (but see Miller et al., 2007; Ding et al., 2012 for evidence of hemodynamic contributions to the diffusion fMRI signal).

\section{THE POSSIBLE PHYSIOLOGICAL BASES OF BOLD FMRI SIGNAL IN WHITE MATTER WHITE MATTER VASCULATURE, CEREBRAL BLOOD FLOW (CBF), AND CEREBRAL BLOOD VOLUME (CBV)}

The vasculature in white matter has been described based on histological methods (Lierse and Horstmann, 1965; Duvernoy et al., 1981), as well as more recently with novel MRI methods. These studies have estimated that the venous vessels in white matter are, on average, approximately the same size as those in gray matter, although the white matter venous vessel density is approximately half the value of gray matter (Jochimsen et al., 2010; Table 1). The microvasculature density of white matter has been estimated using MRI techniques to range from 10-192 microvessels $/ \mathrm{mm}^{2}$ for white matter versus $99-761$ microvessels $/ \mathrm{mm}^{2}$ for gray matter (Jensen et al., 2006). Reduced vascular density can also be observed histologically (Figure 1A; Lierse and Horstmann, 1965). In addition, blood vessels in white matter can be clearly seen during neurosurgery. For example, Figure 1B depicts a blood vessel on the surface of the corpus callosum.

Given the lower density of vessels, it follows that white matter has lower CBF and CBV relative to gray matter (Rostrup et al., 2000; Preibisch and Haase, 2001; Helenius et al., 2003; Table 1). Recent advances in perfusion MRI imaging with arterial spin labeling are allowing white matter cerebral blood flow to be detected in normal healthy volunteers (Figure 1C; Van Osch et al., 2009; Gardener and Jezzard, 2014), providing further 
Table 1 | Factors that influence the ability to detect fMRI activation and how they differ across tissue types.

\begin{tabular}{|c|c|c|c|}
\hline & Gray matter & White matter & Predicted effect on fMRI activation \\
\hline $\begin{array}{l}\text { Cerebral blood } \\
\text { flow (CBF) }\end{array}$ & $\begin{array}{l}50-100 \mathrm{ml} / 100 \mathrm{~g} / \mathrm{min} \text { (Rostrup et al., } \\
\text { 2000; Preibisch and Haase, 2001; } \\
\text { Helenius et al., 2003) }\end{array}$ & $\begin{array}{l}\text { 10-30 ml/100 g/min (Rostrup et al., 2000; } \\
\text { Helenius et al., 2003; Preibisch and Haase, } \\
\text { 2001) }\end{array}$ & $\begin{array}{l}\text { Reduced maximal amplitude of fMRI } \\
\text { responses in white matter. }\end{array}$ \\
\hline $\begin{array}{l}\text { Cerebral blood } \\
\text { volume (CBV) }\end{array}$ & $\begin{array}{l}4.6 \mathrm{ml} / 100 \mathrm{~g} \text { (Helenius et al., 2003) } \\
\text { 1.0-3.3\% capillaries by volume } \\
\text { (Lierse and Horstmann, 1965) }\end{array}$ & $\begin{array}{l}1.3 \mathrm{ml} / 100 \mathrm{~g} \text { (Helenius et al., 2003) } \\
0.3-0.9 \% \text { capillaries by volume (Lierse and } \\
\text { Horstmann, 1965) }\end{array}$ & $\begin{array}{l}\text { Reduced maximal amplitude of } \mathrm{fMRI} \\
\text { responses in white matter. }\end{array}$ \\
\hline Venous vessel size & $\begin{array}{l}13.4 \text { micron radius (Jochimsen et al., } \\
2010 \text { ) } \\
\text { 10-63 micron radius (intracortical } \\
\text { veins; Duvernoy et al., 1981) }\end{array}$ & $\begin{array}{l}13.7 \text { micron radius (Jochimsen et al., 2010) } \\
\text { 30-60 micron radius (Duvernoy et al., } \\
\text { 1981) }\end{array}$ & $\begin{array}{l}\text { If the vessels in white matter are of equal } \\
\text { or greater size than those in gray matter, } \\
\text { one might expect a tendency toward } \\
\text { greater sensitivity in white matter for } \\
\text { standard gradient-echo BOLD sequences } \\
\text { (Boxerman et al., 1995). However, it is } \\
\text { likely that the effect of lower CBF and CBV } \\
\text { in white matter is the dominant factor, } \\
\text { consistent with the notion of reduced } \\
\text { sensitivity to activation in white matter. }\end{array}$ \\
\hline $\mathrm{T} 2 *$ & $\begin{array}{l}89.3 \mathrm{~ms}(1.5 \mathrm{~T}) \\
59.7 \mathrm{~ms}(3 \mathrm{~T}) \\
\text { N.B. Values for cortical gray matter } \\
\text { (Peters et al., 2006) }\end{array}$ & $\begin{array}{l}71.7 \mathrm{~ms}(1.5 \mathrm{~T}) \\
54.6 \mathrm{~ms}(3 \mathrm{~T}) \\
\text { (Peters et al., 2006) }\end{array}$ & $\begin{array}{l}\text { Optimal TE depends on T2*; standard } \\
\text { fMRI parameters may not be optimized for } \\
\text { detecting white matter activation, } \\
\text { particularly at } 1.5 \mathrm{~T} \text { due to greater } \\
\text { differences between the tissue types. }\end{array}$ \\
\hline $\begin{array}{l}\text { Physiological } \\
\text { noise }\end{array}$ & Higher (Bodurka et al., 2007) & Lower (Bodurka et al., 2007) & $\begin{array}{l}\text { White matter fMRI signals may be less } \\
\text { contaminated by physiological noise than } \\
\text { gray matter. }\end{array}$ \\
\hline Tissue geometry & $\begin{array}{l}\text { Cortical gray matter has substantial } \\
\text { potential for PVE with CSF in sulci }\end{array}$ & $\begin{array}{l}\text { Some areas of white matter are very } \\
\text { uniform; others neighbor gray matter } \\
\text { and/or the lateral ventricles }\end{array}$ & $\begin{array}{l}\text { PVEs are problematic throughout white } \\
\text { and gray matter. }\end{array}$ \\
\hline $\begin{array}{l}\text { Categories of } \\
\text { neural activity }\end{array}$ & $\begin{array}{l}\text { Post-synaptic potentials and action } \\
\text { potentials }\end{array}$ & Mostly action potentials & $\begin{array}{l}\text { Both are linked to BOLD fMRI signal } \\
\text { changes (e.g., Logothetis et al., 2001; } \\
\text { Smith et al., 2002). }\end{array}$ \\
\hline $\begin{array}{l}\text { Presence of } \\
\text { activity-dependent } \\
\text { metabolic changes }\end{array}$ & $\begin{array}{l}\text { Observed using numerous } \\
\text { techniques, including calibrated } \\
\text { fMRI (Hoge et al., 1999), PET } \\
\text { (Magistretti, 2006), and optical } \\
\text { imaging (Devor et al., 2012) }\end{array}$ & $\begin{array}{l}\text { Observed using autoradiology (Weber } \\
\text { et al., 2002) }\end{array}$ & $\begin{array}{l}\text { While white matter supports } \\
\text { activity-dependent metabolic changes, the } \\
\text { autoradiography evidence does not } \\
\text { provide sufficient temporal resolution to } \\
\text { imply that such changes might be } \\
\text { detectable with BOLD fMRI. }\end{array}$ \\
\hline Astrocytes & $\begin{array}{l}\text { Positioned to facilitate neurovascular } \\
\text { coupling (Petzold and Murthy, 2011) }\end{array}$ & $\begin{array}{l}\text { Positioned to facilitate neurovascular } \\
\text { coupling (Petzold and Murthy, 2011) }\end{array}$ & $\begin{array}{l}\text { Underlying neurophysiology of gray and } \\
\text { white matter fMRI activation may share } \\
\text { overlapping components. }\end{array}$ \\
\hline
\end{tabular}

confirmation that white matter blood flow is one-tenth to onethird that of gray matter (Table 1). For this reason, it was previously thought that fMRI was sensitive exclusively to gray matter (Logothetis and Wandell, 2004). However, hemodynamic changes can be detected in white matter during vascular challenges, such as breath-holding tasks or hypercapnia (Rostrup et al., 2000; Preibisch and Haase, 2001; Helenius et al., 2003; Macey et al., 2003; Van der Zande et al., 2005; Mandell et al., 2008; Driver et al., 2010; Thomas et al., 2014). Thus, there is evidence that white matter has the vascular capacity to support hemodynamic changes that are detectable with fMRI, particularly at higher magnetic field strengths.

\section{NEUROVASCULAR AND NEUROMETABOLIC COUPLING IN WHITE MATTER}

A crucial question that remains, however, is whether activitydependent hemodynamic changes take place in white matter. Activity-dependent hemodynamic changes are a necessary feature for any neural activity to be detectable with fMRI. Investigations into the neurophysiologic source of fMRI signals have linked the 
signal to post-synaptic potentials, which are mainly localized to gray matter. For example, Logothetis' group showed that BOLD signal changes require only local field potentials (LFPs, which reflect post-synaptic potentials) and can take place in the absence of spiking activity (Rauch et al., 2008). Although there are some synapses and even some cell bodies in white matter (Kukley et al., 2007; García-Marín et al., 2010), post-synaptic potentials account for less than $1 \%$ of the energy demands in white matter (Harris and Attwell, 2012), making white matter post-synaptic potentials unlikely to account for the majority of white matter fMRI signal changes. In white matter, the primary type of neural activity is spiking (which reflects action potentials). Although there is evidence provided that LFPs are sufficient for BOLD signal changes (e.g., Rauch et al., 2008), a relationship between spiking and fMRI activation has also been reported (e.g., Smith et al., 2002), and it remains possible that spiking activity is sufficient for inducing a hemodynamic response (Table 1). It is important to note that the relationship between neural activity and hemodynamic changes has only been studied for gray matter, where post-synaptic potentials do require the majority of energy (Attwell and Laughlin, 2001; Harris and Attwell, 2012).

Given that spiking and LFP activity is inherently correlated, and neurovascular coupling of spikes in the absence of resulting LFPs has not be studied, it is difficult to draw conclusions regarding whether spikes elicit hemodynamic responses. Thus, we consider whether the energetic demands of spiking activity are consistent with a requirement for a measurable hemodynamic response. Spiking is indeed associated with increased activity at energy-dependent ion pumps (Erecińska and Dagani, 1990; Aiello and Bach-y-Rita, 2000). The brain does not have any major energy or oxygen reserves, relying on blood perfusion to meet its metabolic demands (Lecrux and Hamel, 2011). Thus, any spiking related energy demands might result in a hemodynamic response. A crucial factor that remains is whether the magnitude of activity dependent metabolic demands in white matter might reasonably be expected to produce changes of sufficient magnitude to be detected with fMRI.

Harris and Attwell (2012) have proposed an energy budget for white matter, in which they estimate that the energy associated with spiking in white matter comprises only $0.4-7 \%$ of the total energy demand in white matter (depending on myelination status). The vast majority of white matter energy demands are thought to arise from maintaining the resting potential (independent of restoring the ionic gradients due to action potentials) and housekeeping processes such as macromolecule turnover and axoplasmic transport.

A feature not included in Harris and Attwell's (2012) energy budget for spiking is the potential involvement of non-neuronal cell types. Astrocytes exist in white matter (Waxman and Ritchie, 1993; Rash, 2010; Harris and Attwell, 2012), and may perform similar functional roles as gray matter astrocytes. One example is $\mathrm{K}^{+}$siphoning, in which the increase in extracellular $\mathrm{K}^{+}$concentration associated with spiking activity results in increased $\mathrm{K}^{+}$ uptake into astrocytes. Kalsi et al. (2004) found that astrocyte expression of $\mathrm{K}^{+}$channels is localized to perivascular end feet and on processes located within myelinated axon bundles, consistent with a $\mathrm{K}^{+}$siphon function. It has been proposed that $\mathrm{K}^{+}$is first transported across layers of myelin via gap junctions before being taken up by astrocytes (Rash, 2010). Astrocytes then release $\mathrm{K}^{+}$ perivascularly, which relaxes the smooth muscle cells of the arterioles surrounded by the astrocytes' end feet. Thus, $\mathrm{K}^{+}$siphoning is associated with hemodynamic changes, and has been speculated to contribute to neurovascular coupling in gray matter (Petzold and Murthy, 2011). The presence of $\mathrm{K}^{+}$channels in the astrocytes and oligodendrocytes of white matter have been confirmed for the rat optic nerve (Rash, 2010). While diffusion of $\mathrm{K}^{+}$through gap junctions is not an energy-demanding process, as it is driven by an electrochemical gradient, this may be an important pathway linking action potentials and a hemodynamic response.

Recently, Barbaresi et al. (2013) investigated the presence and distribution of nitric oxide (NO) producing neurons in the corpus callosum. Immunohistochemistry techniques revealed NO producing neurons throughout the corpus callosum, with higher density in lateral and caudal regions. Notably, the somatic, dendritic, and axonal processes of many NO producing neurons were found nearby blood vessels in the corpus callosum. Given that NO is a powerful vasodilator, the authors concluded that "NO positive neurons transduce neuronal signals into vascular responses in selected [callosal] regions, thus giving rise to hemodynamic changes detectable by neuroimaging."

In addition to the neurovascular mechanisms speculated above, experimental evidence of activity dependent metabolic changes in white matter has been established. Weber et al. (2002) investigated activity-dependent glucose uptake changes in a rodent model using [18F]fluorodeoxyglucose autoradiography. They reported increased glucose uptake in the corpus callosum associated with electrical stimulation of a cortical region with callosal projections. Furthermore, the increase in glucose uptake was greater for higher frequency stimulation. However, it has not yet been experimentally demonstrated that activity-dependent increases in glucose uptake in white matter are coupled to a hemodynamic response that could be measured with fMRI. In addition, the lack of temporal information available from autoradiography is problematic; the observed increased in metabolic demands associated with spiking rate may occur over too slow a time scale (i.e., many minutes or hours) for this effect to be relevant for typical fMRI experiments (Table 1). For these reasons, it will be important for future studies to experimentally verify whether such metabolic increases are accompanied by fMRI signal changes.

\section{UNDERSTANDING WHY REPORTS OF WHITE MATTER FMRI ACTIVATION ARE UNCOMMON}

As previously stated by Tettamanti et al. (2002), Yarkoni et al. (2009), and Mazerolle et al. (2008), the primary argument against white matter fMRI activation is the historical lack of reports, rather than any fundamental property that would preclude its existence. In fact, it has recently been speculated that fractional changes in fMRI signals may be greater when baseline flow is lower such as in white matter (Ding et al., 2013). In this section, we put forward some explanations for the paucity of white matter fMRI reports and offer rationales to change the common practice of dismissing fMRI signal in white matter. 


\section{SENSITIVITY AND ARTIFACTS Acquisition}

One reason that $\mathrm{fMRI}$ activation in white matter remains scarce in the literature is that signals associated with fMRI activation in white matter are lower in magnitude than those associated with gray matter activation. The smaller signal changes in white matter may be difficult to detect at conventional field strengths (1.5 $\mathrm{T})$. In fact, there is direct evidence that sensitivity to white matter activation increases with field strength (Mazerolle et al., 2013), a phenomenon, which has been extensively reported in gray matter (e.g., Gati et al., 1997). Reports of white matter activation may also be relatively limited because fMRI acquisition parameters have been optimized for detection of gray matter activation. For example, T2 and T2* are different between white and gray matter (Peters et al., 2006; see Table 1), such that the optimal TE may differ between the tissue types.

\section{Analysis}

In addition to acquisition parameters being tailored for gray matter fMRI activation, it is also important to consider potential biases introduced by analysis techniques. Because fMRI is an indirect measure of functional brain activation, the validity of results is regularly evaluated based on what is already known about the functional organization of the brain. That is, because there is rarely a gold standard available for fMRI results to be compared against, experimenter expectations tend to play a major role in evaluating data quality and the validity of results. This sentiment was described by Poline et al. (2006): "neuroscientists or clinicians [typically] assess [fMRI] results in relation to their prior expectations, although this biases $\mathrm{fMRI}$ studies away from making new and unexpected discoveries" (p. 352).

For the vast majority of fMRI analyses, the shape of the HRF is assumed. However, even within gray matter, there is evidence that the shape of the HRF varies between regions (Miezin et al., 2000; Handwerker et al., 2004; Gonzalez-Castillo et al., 2012). Research into the shape of the HRF in white matter has produced conflicting results. One study showed that the shape of the HRF in white matter is the same as the canonical HRF. However, as an initial step, this study restricted the analysis to regions in which activation could be detected using the canonical HRF (Fraser et al., 2012). Other work has demonstrated slower responses in white matter compared to gray matter (Yarkoni et al., 2009). In the case that differences between the gray matter and white matter HRF exist, the use of the gray matter canonical HRF for modeling activation could result in systematic underestimation of white matter activation. More research is needed to evaluate differences in the shape of the HRF between gray matter and white matter, as well as among different white matter regions. Then, the potential benefits of regionally specific HRFs for detecting white matter fMRI activation could be evaluated.

One major analysis practice, which directly biases against detecting white matter fMRI activation is the use of white matter signals as a nuisance regressor (e.g., Leber, 2010). This approach has been recommended as best practice for resting state functional connectivity analyses (Van Dijk et al., 2010). White matter signals have also been used to estimate physiological noise in fMRI data (e.g., Behzadi et al., 2007). In addition, white matter signals have been used to set thresholds such that, for activation to be considered significant, its intensity must exceed that of white matter (Soltanian-Zadeh et al., 2004). Decreases in white matter fMRI activation have also been cited as evidence that a novel denoising procedure was successful (Tohka et al., 2008). This approach is sensible if and only if there are no signals of interest in white matter. If we assume that the existence of interesting signals in white matter cannot be ruled out, then the validity of assigning white matter signals to the noise pool rests on whether white matter is more prone to artifacts than gray matter. For example, Weis et al. (2011) states: "standard EPI sequences as used [by Weis et al. (2011)] are not optimal for detecting white matter activations and the risk of artifacts is augmented" (p. 388). This statement raised the question: what could cause an increase in artifactual activations in a manner specific to white matter, such that selectively discounting signals in white matter would be a valid approach?

\section{Artifacts}

Below, we outline common sources of artifact and consider whether they might preferentially contaminate white matter.

Motion. A common cause of artifactual activation is task-related motion. When participant motion is task-correlated, artifactual activations can occur, particularly at tissue boundaries (Johnstone et al., 2006). Thus, voxels near the boundaries between gray matter and white matter, and between brain parenchyma and CSF, will be most sensitive to motion-induced artifactual activations. White matter voxels per se are unlikely to be more susceptible to false activations due to motion than other voxels. Regions of deep white matter, which can be centimeters away from tissue boundaries, may be particularly insensitive to such artifacts. This is because, in deep white matter, it is unlikely that tissue boundaries would be displaced, which causes apparent changes in signal intensity that can be misidentified as activation. Furthermore, many studies of white matter activation have mitigated the risk of motion-related activations by including the estimated motion parameters (output by the motion correction) as regressors of no interest in the analysis model (Mazerolle et al., 2008; Yarkoni et al., 2009; Gawryluk et al., 2011a,b). Even with this approach, it is possible that nonlinear spin history effects caused by motion are not corrected (Yancey et al., 2011). However, spin history effects are likely to be most severe near regions of large magnetic gradients (i.e., susceptibility induced field gradients near the sinuses) and would not be expected to result in white matter-specific effects.

Partial volume effects. Another reason that some groups have questioned fMRI activation in white matter is the possible attribution of the signal to partial volume effects. Partial volume effects can occur when a voxel exists at the interface multiple tissue types, which renders the source of the signal indistinguishable. This problem can be exacerbated by the use of lowresolution (large) voxels (which offer benefits in SNR) as well as data pre-processing steps such as spatial smoothing. It is possible, for example, that fMRI activation in the internal capsule (Mosier et al., 1999a; Gawryluk et al., 2011b) is the result of signal contamination from nearby subcortical gray matter structures (e.g., Mortiz et al., 2000; Lehéricy et al., 2006). In fact, partial volume 
effects are a universal concern in fMRI; however, there are a few key pieces of evidence that the activation in white matter is not a result of partial volume effects from gray matter signal.

First, the areas in which white matter activation have been reported are functionally consistent with the nature of the given task. For example, activation in the corpus callosum was observed during interhemispheric transfer tasks, as would be expected (Gawryluk et al., 2011a). Second, in the case that a cluster was large enough to cover both white and gray matter voxels, many studies have ensured that a local maximum was co-localized to the white matter structure of interest (e.g., Mazerolle et al., 2013). Indeed, many studies have reported activation that is entirely bounded by white matter tissue, with no adjacent gray matter (e.g., Fraser et al., 2012). Recent work by Mazerolle (2012) has provided further evidence that white matter activation is not a result of partial volume effects. This work also took an analysis approach that used very conservative masks of gray and white matter (thereby reducing/eliminating partial volume effects) on a data set that showed whole brain activation (from a breath hold task). It was determined that the activation seen in white matter was could not be explained solely on the basis of gray matter partial volume (Mazerolle, 2012). Therefore, although partial volume effects should always be considered, it is unlikely that the majority of white matter activation reported can be attributed to partial volume effects (Table 1).

Physiological noise. Another potential source of artifactual activation is physiological noise. When task-correlated, respiratory and cardiac artifacts can result in artifactual activation. Taskcorrelated respiratory and/or cardiac rate changes have been observed for tasks that require attention, are cognitively challenging, or are emotional (Birn et al., 2009). However, Birn et al. (2006) demonstrated that respiratory related artifacts tend to be most problematic in gray matter or near large vessels. This is consistent with findings that tSNR is greater in white matter compared to gray matter (e.g., Bodurka et al., 2007; GonzalezCastillo et al., 2011; Mazerolle et al., 2013). Thus, it is unlikely that white matter is particularly prone to artifactual activation caused by physiological noise (Table 1). Thus, it may be worthwhile re-considering current approaches that define noise to be white matter signals (see Section Analysis), especially given that other voxels in which no neural tissue is contained are available (e.g., CSF).

\section{FUTURE DIRECTIONS IN WHITE MATTER FMRI RESEARCH BASIC RESEARCH}

There is a growing interest in using brain imaging techniques to describe the entire network of connections in the human brain (i.e., map the human connectome; e.g., Sporns, 2012). This research is critical, given that intact brain connectivity is necessary for normal function, and disconnections are implicated in many neurologic and psychiatric conditions (e.g., Charil et al., 2003; White et al., 2008). However, the current methods of studying connectivity lack a direct approach. To date, MRI studies of connectivity have mainly used DTI tractography and functional connectivity analyses. While DTI tractography has permitted significant advances in the current understanding of brain connectivity, the technique is limited to evaluating structure, and does not provide information about the functional dynamics of the identified networks. Information from DTI tractography can be augmented with functional connectivity analyses, which typically infers connectivity based on correlations between the time series of different gray matter regions. Even when combined, DTI tractography and functional connectivity approaches are fundamentally limited by the fact that neither evaluates the functional dynamics directly within white matter pathways. Studying the activation patterns of the white matter pathways is crucial for understanding the interactions among different nodes in a brain network, as well as evaluating whether structural white matter changes are associated with functional changes. This approach may also clarify whether observed correlations between gray matter result from direct connections, or indirect connections mediated by other gray matter areas.

Basic research could also focus on analysis techniques to further optimize the sensitivity to the detection of white matter fMRI activation. For example, it may be possible to increase sensitivity to white matter activation by using a white matter specific HRF. Although there is evidence that the HRF in the corpus callosum resembles the canonical HRF (Fraser et al., 2012), more work is needed to evaluate the HRF in various white matter regions. Relatedly, various fMRI analysis software packages handle data differently (e.g., motion correction, thresholding options; Oakes et al., 2005). Future work could compare different analysis options and determine the selections that are most sensitive to activation in white matter.

A key step to move the field forward will be investigating the neurophysiological basis of white matter fMRI activation. The neural events and signaling pathways underlying fMRI signals are still not fully understood. The vast majority of work on neurovascular coupling has focused on gray matter. By applying this methodology to white matter, we could better understand the underpinnings of white matter fMRI activation. This knowledge would both improve confidence in white matter fMRI activation and enhance the interpretations of such findings.

\section{CLINICAL RESEARCH}

The ability to detect fMRI activation in white matter has clear implications for the evaluation of white matter disease and damage. A key step in linking advances in research to the evaluation of clinical disorders is to use clinical measures of white matter function in fMRI studies. Recently, Gawryluk and colleagues adapted the Symbol Digit Modalities Test, a sensitive measure of processing speed that is associated with white matter integrity (Chiaravalloti and Deluca, 2008) for use with fMRI. The results revealed activation in the corpus callosum and/or internal capsule in $88 \%$ of participants $(N=17$; Gawryluk et al., 2014). The next step in this line of research is to study white mater activation in patient groups. This will be particularly relevant given that findings may vary by disease or condition of the patient and may provide insight into discrepancies between structural neuroimaging findings and symptomology (Pelletier et al., 2009).

Another consideration in terms of preparing white matter fMRI for clinical applications, the main challenge will be in developing a comprehensive approach. The majority of the white 
matter fMRI studies to date have elicited activation in the corpus callosum and internal capsule. Although these structures are often involved in white matter disorder, an ideal and thorough assessment of white matter function should be able to evaluate multiple regions. Such an evaluation would likely require a battery approach in which a variety of short tasks could be administered to study specified areas of interest. Tests developed for a battery should also be studied in a large group of individuals to document the variability associated with a given task.

However, a battery approach may not always be practical given constraints on scanner time and patient comfort and performance. In gray matter, the suitability of a task-free (i.e., resting state) connectivity approach to evaluate the functional status of the tissue in all brain networks has recently been considered, with promising results (e.g. Liu et al., 2009). This has significant advances over a task battery approach with respect to scan duration and patient compliance requirements. While there may be additional hurdles applying this approach to the functional assessment of white matter given the smaller magnitude of changes expected, recent results demonstrating resting state functional connectivity within white matter pathways is promising (Ding et al., 2013).

Whether a battery or task-free functional connectivity approach is used, quantification of within-subject reliability of white matter activation will be necessary to interpret results in patients. Reliability is an active area of fMRI research. Varying degrees of reliability have been reported for gray matter activation, depending on the analysis technique, reliability metric, testretest interval, as well as the particular tasks and regions of interest (reviewed in Bennett and Miller, 2010). Regional differences in reliability may be explained in part by the local microvasculature. For example, McGonigle et al. (2000) speculated that high variability in visual cortex may be partially due to the high concentration of venules in the region, allowing a wider range of responses to visual stimulation. Thus, it is important to evaluate reliability specifically for white matter fMRI activation, particularly given the known differences in vasculature, CBF, and CBV in white matter relative to gray matter (Duvernoy et al., 1981; Rostrup et al., 2000; Preibisch and Haase, 2001; Helenius et al., 2003). Clinically, this question becomes highly relevant when assessing patients with white matter disorder over time in order to distinguish between real changes versus normal variability.

\section{CONCLUSIONS}

Functional MRI is a tremendous technique that has allowed for noninvasive visualization of functional dynamics in the human brain. However, a major limitation of fMRI is that it is typically only used to study gray matter, which merely represents half of the brain. Conventionally, white matter tissue has only been examined using structural measures that do not always correlate well with measures of function (Pelletier et al., 2009). However, a growing body of work supports the notion that fMRI can be used to study functional dynamics in white matter. This approach is increasingly being applied to provide novel insights into brain connectivity. The ability to detect activation in the brain's connections will open new research avenues into how the regions within brain networks interact to support complex cognitive functions. White matter fMRI will also provide valuable insight into a number of disorders and conditions, including multiple sclerosis, diffuse axonal injury, degenerative diseases, and neurosurgical patients. Taken together, the advances presented in this review provide support for a more direct method of studying and evaluating white matter function with $\mathrm{fMRI}$.

\section{AUTHOR CONTRIBUTIONS}

Jodie R. Gawryluk and Erin L. Mazerolle generated the content and drafted the review manuscript. Ryan C. N. D'Arcy led the research program and revised the review manuscript draft.

\section{ACKNOWLEDGMENTS}

Thanks are extended to Dr. Steven Beyea and the other members of National Research Council's (NRC) Institute for Biodiagnostics (Atlantic) for their contributions to the research discussed in this review paper. Erin L. Mazerolle was supported by the Natural Sciences and Engineering Research Council of Canada (NSERC), the CIBC Fellowship in Brain Imaging (Montreal Neurological Institute), Alberta Innovates Health Solutions, and the NSERC CREATE I3T Program. Jodie R. Gawryluk was supported by the Scottish Rite Charitable Foundation and the Nova Scotia Health Research Foundation. Ryan C. N. D'Arcy and the overall research program were funded by NRC (imaging infrastructure), NSERC Discovery Grants (basic science experiments), and the Canadian Institutes for Health Research (CIHR; clinical translation experiments). Thanks are extended to Dr. David Clarke for permission to obtain intraoperative photographs of the corpus callosum and Dr. Rebecca J. Williams for helpful feedback on the revisions.

\section{SUPPLEMENTARY MATERIAL}

The Supplementary Material for this article can be found online at: http://www.frontiersin.org/journal/10.3389/fnins. 2014.00239/abstract

\section{REFERENCES}

Aiello, G. L., and Bach-y-Rita, P. (2000). The cost of an action potential. J. Neurosci. Methods 103, 145-149. doi: 10.1016/S0165-0270(00)00308-3

Arai, K., and Lo, E. G. (2009). Oligovascular signalling in white matter stroke. Biol. Pharm. Bull. 32, 1639-1644. doi: 10.1248/bpb.32.1639

Aramaki, U., Honda, M., Okada, T., and Sadato, N. (2006). Neural correlates of the spontaneous phase transition during bimanual coordination. Cereb. Cortex 16, 1338-1348. doi: 10.1093/cercor/bhj075

Attwell, D., and Laughlin, S. B. (2001). An energy budget for signalling in the grey matter of the brain. J. Cereb. Blood Flow Metab. 21, 1133-1145. doi: 10.1097/00004647-200110000-00001

Bandettini, P. A. (2012). Functional MRI: a confluence of fortunate circumstances. Neuroimage 61, A3-A11. doi: 10.1016/j.neuroimage.2012.01.130

Barbaresi, P., Fabri, M., and Mensa, E. (2013). Characterization of NOproducing neurons in the rat corpus callosum. Brain Behav. 4, 317-336. doi: 10.1002/brb3.218

Behzadi, Y., Restom, K., Liau, J., and Liu, T. T. (2007). A component based noise correction method (CompCor) for BOLD and perfusion based fMRI. Neuroimage 37, 90-101. doi: 10.1016/j.neuroimage.2007.04.042

Bennett, C. M., and Miller, M. B. (2010). How reliable are the results from functional magnetic resonance imaging? Ann. N.Y. Acad. Sci. 1191, 133-155. doi: 10.1111/j.1749-6632.2010.05446.x

Birn, R. M., Diamond, J. B., Smith, M. A., and Bandettini, P. (2006). Separating respiratory-variation related fluctuations from neuronal-activity-related fluctuations in fMRI. Neuroimage 31, 1536-1548. doi: 10.1016/j.neuroimage.2006. 02.048 
Birn, R. M., Murphy, K., Handwerker, D. A., and Bandettini, P. (2009). fMRI in the presence of task correlated breathing variations. Neuroimage 47, 1092-1104. doi: 10.1016/j.neuroimage.2009.05.030

Black, S. E. (2007). Imaging white matter and the burden of small vessel disease. Brain Cogn. 63, 191-196. doi: 10.1016/j.bandc.2006.08.010

Bodurka, J., Ye, F., Petridou, N., Murphy, K., and Bandettini, P. A. (2007). Mapping the MRI voxel volume in which thermal noise matches physiological noise - implications for fMRI. Neuroimage 34, 542-549. doi: 10.1016/j.neuroimage.2006.09.039

Boxerman, J. L., Hamberg, L. M., Rosen, B. R., and Weisskoff, R. M. (1995). MR contrast due to intravascular magnetic susceptibility perturbations. Magn. Reson. Med. 34, 555-566. doi: 10.1002/mrm.1910340412

Brandt, T., Stephan, T., Bense, S., Yousry, T.A., and Dieterich, M. (2000). Hemifield visual motion stimulation: an example of interhemispheric crosstalk. Neuroreport 11, 2803-2809. doi: 10.1097/00001756-200008210-00039

Catani, M., and ffytche, D. H. (2005). The rises and falls of disconnection syndromes. Brain 128, 2224-2239. doi: 10.1093/brain/awh622

Charil, A., Zijdenbos, A. P., Taylor, J., Boelman, C., Worsley, K. J., Evans, A. C., et al. (2003). Statistical mapping analysis of lesion location and neurological disability in multiple sclerosis: application to 452 patient data sets. Neuroimage 19, 532-544. doi: 10.1016/S1053-8119(03)00117-4

Chiaravalloti, N. D., and Deluca, J. (2008). Cognitive impairment in multiple sclerosis. Lancet Neurol. 7, 1139-1151. doi: 10.1016/S1474-4422(08)70259-X

Chiu, M. J., Lin, C. C., Chuang, K. H., Chen, J. H, and Huang, K. M. (2001). Tissue segmentation assisted analysis of fMRI for human motor response: an approach combining artificial neural network and fuzzy C means. J. Digit. Imaging 14, 38-47. doi: 10.1007/s10278-001-0023-y

D'Arcy, R. C. N., Hamilton, A., Jarmasz, M., Sullivan, S., and Stroink, G. (2006). Exploratory data analysis reveals visuovisual interhemispheric transfer in functional magnetic resonance imaging. Magn. Reson. Med. 55, 952-958. doi: 10.1002/mrm.20839

Darquié, A., Poline, J. B., Poupon, C., Saint-Jalmes, H., and Le Bihan, D. (2001). Transient decrease in water diffusion observed in human occipital cortex during visual stimulation. Proc. Natl. Acad. Sci. U.S.A. 98, 9391-9395. doi: 10.1073/pnas.151125698

Devor, A., Sakadžić, S., Srinivasan, V. J., Yaseen, M. A., Nizar, K., Saisan, P. A., et al. (2012). Frontiers in optical imaging of cerebral blood flow and metabolism. $J$. Cereb. Blood. Flow Metab. 32, 1259-1276. doi: 10.1038/jcbfm.2011.195

Ding, A. Y., Chan, K. C., and Wu, E. X. (2012). Effect of cerebrovascular changes in brain DTI quantitation: a hypercapnia study. Magn. Reson. Imaging 30, 993-1001. doi: 10.1016/j.mri.2012.02.012

Ding, Z., Newton, A. T., Xu, R., Anderson, A. W., Morgan, V. L., and Gore, J. C. (2013). Spatio-temporal correlation tensors reveal functional structure in human brain. PLoS ONE 8:e82107. doi: 10.1371/journal.pone.0082107

Dolan, R. J. (2008). Neuroimaging of cognition: past, present, and future. Neuron 60, 496-502. doi: 10.1016/j.neuron.2008.10.038

Driver, I., Blockley, N., Fisher, J., Francis, S., and Gowland, P. (2010). The change in cerebrovascular reactivity between $3 \mathrm{~T}$ and $7 \mathrm{~T}$ measured using graded hypercapnia. Neuroimage 51, 274-279. doi: 10.1016/j.neuroimage.2009.12.113

Duvernoy, H. M., Delon, S., and Vannson, J. L. (1981). Cortical blood vessels of the human brain. Brain. Res. Bull. 7, 519-579. doi: 10.1016/0361-9230(81) 90007-1

Erecińska, M., and Dagani, F. (1990). Relationships between the neuronal sodium/potassium pump and energy metabolism. Effects of $\mathrm{K}^{+}, \mathrm{Na}^{+}$, and adenosine triphosphate in isolated brain synaptosomes. J. Gen. Physiol. 95, 591-616. doi: 10.1085/jgp.95.4.591

Fabri, M., and Polonara, G. (2013). Functional topography of human corpus callosum: an fMRI mapping study. Neural Plast. 2013, 251308. doi: $10.1155 / 2013 / 251308$

Fabri, M., Polonara, G., Mascioli, G., Salvolini, U., and Manzoni, T. (2011). Topographical organization of human corpus callosum: an fMRI mapping study. Brain Res. 1370, 99-111. doi: 10.1016/j.brainres.2010.11.039

Fraser, L. M., Stevens, M. T., Beyea, S. D., and D'Arcy, R. C. N. (2012). White versus gray matter: fMRI hemodynamic responses show similar characteristics, but differ in peak amplitude. BMC Neurosci. 13:91. doi: 10.1186/1471-2202-13-91

García-Marín, V., Blazquez-Llorca, L., Rodriguez, J. R., Gonzalez-Soriano, J., and DeFelipe, J. (2010). Differential distribution of neurons in the gyral white matter of the human cerebral cortex. J. Comp. Neurol. 518, 4740-4759. doi: $10.1002 / \mathrm{cne} .22485$
Gardener, A. G., and Jezzard, P. (2014). Investigating white matter perfusion using optimal sampling strategy arterial spin labeling at 7 tesla. Magn. Reson. Med. doi: 10.1002/mrm.25333. [Epub ahead print].

Gati, J. S., Menon, R. S., Uğurbil, K., and Rutt, B. K. (1997). Experimental determination of the BOLD field strength dependence in vessels and tissue. Magn. Reson. Med. 38, 296-302. doi: 10.1002/mrm.1910380220

Gawryluk, J. R., Brewer, K. D., Beyea, S. D., and D’Arcy, R. C. N. (2009). Optimizing the detection of white matter fMRI using asymmetric spin echo spiral. Neuroimage 45, 83-88. doi: 10.1016/j.neuroimage.2008.11.005

Gawryluk, J. R., D’Arcy, R. C. N., Mazerolle, E. L., Brewer, K. D., and Beyea, S. D. (2011a). Functional mapping in the corpus callosum: a $4 \mathrm{~T}$ fMRI study of white matter. Neuroimage 54, 10-15. doi: 10.1016/j.neuroimage.2010. 07.028

Gawryluk, J. R., Mazerolle, E. L., Beyea, S. D., and D'Arcy, R. C. N. (2014). Functional MRI activation in white matter during the symbol digit modalities test. Front. Hum. Neurosci. 8:589. doi: 10.3389/fnhum.2014.00589

Gawryluk, J. R., Mazerolle, E. L., Brewer, K. D., Beyea, S. D., and D’Arcy, R. C. N. (2011b). Investigation of fMRI activation in the internal capsule. BMC Neurosci. 12:56. doi: 10.1186/1471-2202-12-56

Gazzaniga, M. S., Bogen, J. E., and Sperry, R. W. (1965). Observations on visual perception after disconnexion of the cerebral hemispheres in man. Brain 88, 221-236. doi: 10.1093/brain/88.2.221

Gonzalez-Castillo, J., Roopchansingh, V., Bandettini, P. A., and Bodurka, J. (2011). Physiological noise effects on the flip angle selection in BOLD fMRI. Neuroimage 54, 2764-2778. doi: 10.1016/j.neuroimage.2010.11.020

Gonzalez-Castillo, J., Saad, Z. S., Handwerker, D. A., Inati, S. J., Brenowitz, N., and Bandettini, P. A. (2012). Whole-brain, time-locked activation with simple tasks revealed using massive averaging and model-free analysis. Proc. Natl. Acad. Sci. U.S.A. 109, 5487-5492. doi: 10.1073/pnas.1121049109

Haller, S., and Bartsch, A. J. (2009). Pitfalls in fMRI. Eur. Radiol. 19, 2689-2706. doi: 10.1007/s00330-009-1456-9

Handwerker, D. A., Ollinger, J. M., and D'Esposito, M. (2004). Variation of BOLD hemodynamic responses across subjects and brain regions and their effects on statistical analysis. Neuroimage 21, 1639-1651. doi: 10.1016/j.neuroimage.2003.11.029

Harris, J. J., and Attwell, D. (2012). The energetics of CNS white matter. J. Neurosci. 32, 356-371. doi: 10.1523/JNEUROSCI.3430-11.2012

Helenius, J., Perkiö, J., Soinne, L., Østergaard, L., Carano, R. A. D., Salonen, O., et al. (2003). Cerebral hemodynamics in a healthy population measured by dynamic susceptibility contrast MR imaging. Acta Radiol. 44, 538-546. doi: 10.1080/j.1600-0455.2003.00104.x

Hoge, R. D., Atkinson, J., Gill, B., Crelier, G. R., Marrett, S., and Pike, G. B. (1999). Linear coupling between cerebral blood flow and oxygen consumption in activated human cortex. Proc. Natl. Acad. Sci. U.S.A. 96, 9403-9408. doi: 10.1073/ pnas.96.16.9403

Jensen, J. H., Lu, H., and Inglese, M. (2006). Microvessel density estimation in the human brain by means of dynamic contrast-enhanced echo-planar imaging. Magn. Reson. Med. 56, 1145-1150. doi: 10.1002/mrm.21052

Jochimsen, T. H., Ivanov, D., Ott, D. V. M., Heinke, W., Turner, R., Möller, H. E., et al. (2010). Whole-brain mapping of venous vessel size in humans using the hypercapnia-induced BOLD effect. Neuroimage 51, 765-774. doi: 10.1016/j.neuroimage.2010.02.037

Johnstone, T., Ores Walsh, K. S., Greischar, L. L., Alexander, A. L., Fox, A. S., Davidson, R. J., et al. (2006). Motion correction and the use of motion covariates in multiple-subject fMRI analysis. Hum. Brain Mapp. 27, 779-788. doi: 10.1002/hbm.20219

Kalsi, A. S., Greenwood, K., Wilkin, G., and Butt, A. M. (2004). Kir4.1 expression by astrocytes and oligodendrocytes in CNS white matter: a developmental study in the rat optic nerve. J. Anat. 204, 475-485. doi: 10.1111/j.00218782.2004.00288.x

Kukley, M., Capetillo-Zarate, E., and Dietrich, D. (2007). Vesicular glutamate release from axons in white matter. Nat. Neurosci. 10, 311-320. doi: $10.1038 / \mathrm{nn} 1850$

Leber, A. B. (2010). Neural predictors of within-subject fluctuations in attentional control. J. Neurosci. 30, 11458-11465. doi: 10.1523/JNEUROSCI.0809-10.2010

Le Bihan, D. (2012). Diffusion, confusion and functional MRI. Neuroimage 62, 1131-1136. doi: 10.1016/j.neuroimage.2011.09.058

Lecrux, C., and Hamel, E. (2011). The neurovascular unit in brain function and disease. Acta Physiol. 203, 47-59. doi: 10.1111/j.1748-1716.2011.02256.x 
Lehéricy, S., Bardinet, E., Tremblay, L., Van de Moortele, P. F., Pochon, J. B., Dormont, D., et al. (2006). Motor control in basal ganglia circuits using fMRI and brain atlas approaches. Cereb. Cortex 16, 149-161. doi: 10.1093/cercor/bhi089

Lierse, W., and Horstmann, E. (1965). Quantitative anatomy of the cerebral vascular bed with especial emphasis on homogeneity and inhomogeneity in small parts of the gray and white matter. Acta Neurol. Scand. 41, 15-19. doi: 10.1111/j.1600-0404.1965.tb01946.x

Lin, T. H., Spees, W. M., Chiang, C. W., Trinkaus, K., Cross, A. H., and Song, S. K. (2014). Diffusion fMRI detects white-matter dysfunction in mice with acute optic neuritis. Neurobiol. Dis. 67, 1-8. doi: 10.1016/j.nbd.2014.02.007

Liu, H., Buckner, R. L., Talukdar, T., Tanaka, N., Madsen, J. R., and Stufflebeam, S. M. (2009). Task-free presurgical mapping using functional magnetic resonance imaging intrinsic activity. J. Neurosurg. 111, 746-754. doi: 10.3171/2008.10.JNS08846

Logothetis, N. K., Pauls, J., Augath, M., Trinath, T., and Oeltermann, A. (2001). Neurophysiological investigation of the basis of the fMRI signal. Nature 412, 150-157. doi: 10.1038/35084005

Logothetis, N. K., and Wandell, B. A. (2004). Interpreting the BOLD signal. Annu. Rev. Physiol. 66, 735-769. doi: 10.1146/annurev.physiol.66.082602.092845

Macey, P. M., Alger, J. R., Kumar, R., Macey, K. E., Woo, M. A., and Harper, R. M. (2003). Global BOLD MRI changes to ventilatory challenges in congenital central hypoventilation syndrome. Respir. Physiol. Neurobiol. 139, 41-50. doi: 10.1016/j.resp.2003.09.006

Magistretti, P. J. (2006). Neuron-glia metabolic coupling and plasticity. J. Exp. Biol. 209, 2304-2311. doi: 10.1242/jeb.02208

Mandell, D. M., Han, J. S., Poublanc, J., Crawley, A. P., Kassner, A., Fisher, J. A., et al. (2008). Selective reduction of blood flow to white matter during hypercapnia corresponds with leukoaraiosis. Stroke 39, 1993-1998. doi: 10.1161/STROKEAHA.107.501692

Mandl, R. C. W., Schnack, H. G., Zwiers, M. P., van der Schaaf, A., Kahn, R. S., and Hulshoff Pol, H. E. (2008). Functional diffusion tensor imaging: measuring task-related fractional anisotropy changes in the human brain along white matter tracts. PLoS ONE 3:e3631. doi: 10.1371/journal.pone.0003631

Mazerolle, E.L. (2012). Refinements to the Current Understanding of Functional MRI Activation in White Matter. Ph.D. thesis, Dalhousie University.

Mazerolle, E. L., Beyea, S. D., Gawryluk, J. R., Brewer, K. D., Bowen, C. V., and D'Arcy, R. C. N. (2010). Confirming white matter fMRI activation in the corpus callosum: colocalization with DTI tractography. Neuroimage 50, 616-621. doi: 10.1016/j.neuroimage.2009.12.102

Mazerolle, E. L., D’Arcy, R. C. N., and Beyea, S. D. (2008). Detecting functional magnetic resonance imaging activation in white matter: interhemispheric transfer across the corpus callosum. BMC Neurosci. 9:84. doi: 10.1186/14712202-9-84

Mazerolle, E. L., Gawryluk, J. R., Dillen, K. N. H., Patterson, S. A., Feindel, K. W., Beyea, S. D., et al. (2013). Sensitivity to white matter fMRI activation Increases with field strength. PLOS ONE 8:e58130. doi: 10.1371/journal.pone. 0058130

McGonigle, D. J., Howseman, A. M., Athwal, B. S., Friston, K. J., Frackowiak, R. S. J., and Holmes, A. P. (2000). Variability in fMRI: an examination of intersession differences. Neuroimage 11, 708-734. doi: 10.1006/nimg.2000.0562

McWhinney, S. R., Mazerolle, E. L., Gawryluk, J. R., Beyea, S. D., and D'Arcy, R. C.N. (2012). Comparing gray and white matter fMRI activation using asymmetric spin echo spiral. J. Neurosci. Methods 209, 351-356. doi: 10.1016/j.jneumeth.2012.06.014

Miezin, F. M., Maccotta, L., Ollinger, J. M., Petersen, S. E., and Buckner, R. L. (2000). Characterizing the hemodynamic response: effects of presentation rate, sampling procedure, and the possibility of ordering brain activity based on relative timing. Neuroimage 11, 735-759. doi: 10.1006/nimg.2000.0568

Miller, K. L., Bulte, D. P., Devlin, H., Robson, M. D., Wise, R. G., Woolrich, M. W., et al. (2007). Evidence for a vascular contribution to diffusion FMRI at high b value. Proc. Natl. Acad. Sci. U.S.A. 104, 20967-20972. doi: 10.1073/pnas.0707257105

Mortiz, C. H., Meyerand, E., Cordes, D., and Haughton, V. M. (2000). Functional MR imaging activation after finger tapping has a shorter duration in the basal ganglia than in the sensorimotor cortex. Am. J. Neuroradiol. 21, 1228-1234.

Mosier, K., and Bereznaya, I. (2001). Parallel cortical networks for volitional control of swallowing in humans. Exp. Brain Res. 140, 280-289. doi: $10.1007 / \mathrm{s} 002210100813$
Mosier, K., Liu, W. C., Maldjian, J. A., Shah, R., and Modi, B. (1999a). Lateralization of cortical function in swallowing: a functional MR imaging study. Am. J. Neuroradiol. 20, 120-1526.

Mosier, K., Patel, R., Liu, W. C., Kalnin, A., Maldjian, J., and Baredes, S. (1999b). Cortical representation of swallowing in normal adults: functional implications. Laryngoscope 109, 1417-1423. doi: 10.1097/00005537-19990900000011

Myers, J. J., and Sperry, R. W. (1985). Interhemispheric communication after section of the forebrain commissures. Cortex 21, 249-260. doi: 10.1016/S00109452(85)80030-7

Newman, A. J., Supalla, T., Hauser, P., Newport, E. L., and Bavelier, D. (2010). Dissociating neural subsystems for grammar by contrasting word order and inflection. Proc. Natl. Acad. Sci. U.S.A. 107, 7539-7544. doi: 10.1073/pnas.1003174107

Oakes, T. R., Johnstone, T., Ores Walsh, K. S., Greischar, L. L., Alexander, A. L., Fox, A. S., et al. (2005). Comparison of fMRI motion correction software tools. Neuroimage 28, 529-543. doi: 10.1016/j.neuroimage.2005.05.058

Ogawa, S., Tank, D. W., Menon, R., Ellermann, J. M., Kim, S. G., Merkle, H., et al. (1992). Intrinsic signal changes accompanying sensory stimulation: functional brain mapping with magnetic resonance imaging. Proc. Natl. Acad. Sci. U.S.A. 89, 5951-5955. doi: 10.1073/pnas.89.13.5951

Omura, K., Tsukamoto, T., Kotani, Y., Ohgami, Y., Minami, M., and Inoue, Y. (2004). Different mechanisms involved in interhemispheric transfer of visuomotor information. Neuroreport 15, 2707-2711.

Pelletier, J., Audoin, B., Reuter, F., and Ranjeva, J. (2009). Plasticity in MS: from functional imaging to rehabilitation. Int. MS J. 16, 26-31.

Peters, A. M., Brookes, M. J., Hoogenraad, F. G. C., Gowland, P. A., and Tracey, S. (2006). "Comparison of T2* measurements in human brain at 1.5, 3 and $7 \mathrm{~T}$," in Proceedings of the International Society for Magnetic Resonance in Medicine 14th Scientific Meeting (Seattle, WA).

Petzold, G. C., and Murthy, V. N. (2011). Role of astrocytes in neurovascular coupling. Neuron 71, 782-797. doi: 10.1016/j.neuron.2011.08.009

Poffenberger, A. T. (1912). Reaction time to retinal stimulation with special reference to the time lost in conduction through nervous centers. Arch. Psychol. 23, $1-73$.

Poline, J. B., Strother, S. C., Dehaene-Lambertz, G., Egan, G. F., and Lancaster, J. L. (2006). Motivation and synthesis of the FIAC experiment: reproducibility of fMRI results across expert analyses. Hum. Brain Mapp. 27, 351-359. doi: 10.1002/hbm.20268

Preibisch, C., and Haase, A. (2001). Perfusion imaging using spin labeling methods: contrast-to-noise comparison in functional MRI applications. Magn. Reson. Med. 46, 172-182. doi: 10.1002/mrm.1173

Rash, J. E. (2010). Molecular disruptions of the panglial syncytium block potassium siphoning and axonal saltatory conduction: pertinence to neuromyelitis optica and other demyelinating diseases of the central nervous system. Neuroscience 168, 982-1008. doi: 10.1016/j.neuroscience.2009.10.028

Rauch, A., Rainer, G., Augath, M., Oeltermann, A., and Logothetis, N. K. (2008). Pharmacological MRI combined with electrophysiology in non-human primates: effects of lidocaine on primary visual cortex. Neuroimage 40, 590-600. doi: 10.1016/j.neuroimage.2007.12.009

Rosen, B. R., Buckner, R. L., and Dale, A. M. (1998). Event-related functional MRI: past, present, and future. Proc. Natl. Acad. Sci. U.S.A. 95, 773-780. doi: 10.1073/pnas.95.3.773

Rosen, B. R., and Savoy, R. L. (2012). fMRI at 20: Has it changed the world? Neuroimage 62, 1316-1324. doi: 10.1016/j.neuroimage.2012.03.004

Rostrup, E., Law, I., Blinkenberg, M., Larsson, H. B. W., Born, A. P., Holm, S., et al. (2000). Regional differences in the CBF and BOLD responses to hypercapnia: a combined PET and fMRI study. Neuroimage 11, 87-97. doi: 10.1006/nimg.1999.0526

Shuster, L. I., Moore, D. R., Chen, G., Ruscello, D. M., and Wonderlin, W. F. (2014). Does experience in talking facilitate speech repetition? Neuroimage 87, 80-88. doi: 10.1016/j.neuroimage.2013.10.064

Smith, A. J., Blumenfeld, H., Behar, K. L., Rothman, D. L., Shulman, R. G., and Hyder, F. (2002). Cerebral energetics and spiking frequency: the neurophysiological basis of fMRI. Proc. Natl. Acad. Sci. U.S.A. 99, 10765-10770. doi: 10.1073/pnas.132272199

Soltanian-Zadeh, H., Peck, D. J., Hearshen, D. O., and Lajiness-O'Neill, R. R. (2004). Model independent method for fMRI analysis. IEEE Trans. Med. Imaging 23, 285-296. doi: 10.1109/TMI.2003.823064 
Spees, W. M., Lin, T. H., and Song, S. K. (2013). White-matter diffusion fMRI of mouse optic nerve. Neuroimage 65, 209-215. doi: 10.1016/j.neuroimage.2012. 10.021

Sporns, O. (2012). From simple graphs to the connectome: networks in neuroimaging. NeuroImage 62, 881-886. doi: 10.1016/j.neuroimage.2012.08.085

Tettamanti, M., Paulesu, E., Scifo, P., Maravita, A., Fazio, F., Perani, D., et al. (2002). Interhemispheric transmission of visuomotor information in humans: fMRI evidence. J. Neurophysiol. 88, 1051-1058.

Thomas, B. P., Liu, P., Park, D. C., van Osch, M. J. P., and Lu, H. (2014). Cerebrovascular reactivity in the brain white matter: magnitude, temporal characteristics, and age effects. J. Cereb. Blood Flow Metab. 34, 242-247. doi: 10.1038/jcbfm.2013.194

Thyreau, B., Schwartz, Y., Thirion, B., Frouin, V., Loth, E., Vollstädt-Klein, S. et al. (2012). Very large fMRI study using the IMAGEN database: sensitivityspecificity and population effect modeling in relation to the underlying anatomy. NeuroImage 61, 295-303. doi: 10.1016/j.neuroimage.2012.02.083

Tohka, J., Foerde, K., Aron, A. R., Tom, S. M., Toga, A. W., and Poldrack, R. A. (2008). Automatic independent component labeling for artifact removal in fMRI. Neuroimage 39, 1227-1245. doi: 10.1016/j.neuroimage.2007.10.013

Van der Zande, F. H. R., Hofman, P. A. M., and Backes, W. H. (2005). Mapping hypercapnia induced cerebrovascular reactivity using BOLD fMRI. Neuroradiology 47, 114-120. doi: 10.1007/s00234-004-1274-3

Van Dijk, K. R. A., Hedden, T., Vekataraman, A., Evans, K. C., Lazar, S. W., and Buckner, R. L. (2010). Intrinsic functional connectivity as a tool for human connectomics: theory, properties, and optimization. J. Neurophysiol. 103, 297-321. doi: 10.1152/jn.00783.2009

Van Osch, M. J. P., Teeuwisse, W. M., van Walderveen, M. A. A., Hendrikse, J., Kies, D. A., and van Buchem, M. A. (2009). Can arterial spin labeling detect white matter perfusion signal? Magn. Reson. Med. 62, 165-173. doi: 10.1002/ mrm.22002

Wang, X., Chan, S. T., Fang, J., Nixon, E. E., Liu, J., Kwong, K. K., et al. (2013). Neural encoding of acupuncture needling sensations: evidence from a fMRI study. Evid. Based Complement. Alternat. Med. 2013:483105. doi: 10.1155/2013/ 483105

Waxman, S. G., and Ritchie, J. M. (1993). Molecular dissection of the myelinated axon. Ann. Neurol. 33, 121-136. doi: 10.1002/ana.410330202

Weber, B., Fouad, K., Burger, C., and Buck, A. (2002). White matter glucose metabolism during intracortical electrostimulation: a quantitative [18F]Fluorodeoxyglucose autoradiography study in the rat. Neuroimage 16, 993-998. doi: 10.1006/nimg.2002.1104
Weber, B., Treyer, V., Oberholzer, N., Jaermann, T., Boesiger, P., Brugger, P., et al. (2005). Attention and interhemispheric transfer: a behavioural and fMRI study. J. Cogn. Neurosci. 17, 113-123. doi: 10.1162/0898929052 880002

Weis, S., Leube, D., Erb, M., Heun, R., Grodd, W., and Kircher, T. (2011). Functional neuroanatomy of sustained memory encoding performance in healthy aging and in Alzheimer's disease. Int. J. Neurosci. 121, 384-392. doi: 10.3109/00207454.2011.565892

White, T., Nelson, M., and Lim, K. O. (2008). Diffusion tensor imaging in psychiatric disorders. Top. Magn. Reson. Imaging 19, 97-109. doi: 10.1097/RMR.0b013 e3181809fle

Williams, R. J., McMahon, K. L., Hocking, J., and Reutens, D. C. (2013) Comparison of block and event-related experimental designs in diffusionweighted functional MRI. J. Magn. Reson. Imaging 40, 367-375. doi: 10.1002/ jmri.24353

Yancey, S. E., Rotenberg, D. J., Tam, F., Chiew, M., Ranieri, S., Biswas, L., et al. (2011). Spin-history artifact during functional MRI: potential for adaptive correction. Med. Phys. 38, 4634-4646. doi: 10.1118/ 1.3583814

Yarkoni, T., Barch, D. M., Gray, J. R., Conturo, T. E., and Braver, T. S. (2009). BOLD correlates of trial-by-trial reaction time variability in gray and white matter a multi-study fMRI analysis. PLoS ONE 4:e4257. doi: 10.1371/journal.pone.0004257

Conflict of Interest Statement: The authors declare that the research was conducted in the absence of any commercial or financial relationships that could be construed as a potential conflict of interest.

Received: 18 May 2014; accepted: 21 July 2014; published online: 08 August 2014. Citation: Gawryluk JR, Mazerolle EL and D'Arcy RCN (2014) Does functional MRI detect activation in white matter? A review of emerging evidence, issues, and future directions. Front. Neurosci. 8:239. doi: 10.3389/fnins.2014.00239

This article was submitted to Brain Imaging Methods, a section of the journal Frontiers in Neuroscience.

Copyright (C) 2014 Gawryluk, Mazerolle and D'Arcy. This is an open-access article distributed under the terms of the Creative Commons Attribution License (CC BY). The use, distribution or reproduction in other forums is permitted, provided the original author(s) or licensor are credited and that the original publication in this journal is cited, in accordance with accepted academic practice. No use, distribution or reproduction is permitted which does not comply with these terms. 